\title{
Diastolic untwisting is altered in patients with congenital heart disease: a novel MR speckle tracking method for cine-MRI Petra S Niemann*1, Helene Houle ${ }^{2}$, Craig S Broberg1, Michael Silberbach ${ }^{1}$, Zhiwen Zhou $^{1}$, Muhammad Ashraf ${ }^{1}$ and David J Sahn ${ }^{1}$
}

\begin{abstract}
Address: ${ }^{1}$ Oregon Health \& Science University, Portland, OR, USA and ${ }^{2}$ Siemens Medical Solutions, Mountain View, CA, USA
\end{abstract}
* Corresponding author

from 13th Annual SCMR Scientific Sessions

Phoenix, AZ, USA. 21-24 January 2010

Published: 21 January 2010

Journal of Cardiovascular Magnetic Resonance 2010, I2(SuppI I):PI9 doi:I0.1 186/1532-429X-I2-SI-PI9

This abstract is available from: http://jcmr-online.com/content/I2/SI/PI 9

(c) 2010 Niemann et al; licensee BioMed Central Ltd.

\section{Introduction}

In patients with CHD (CO, ASD, VSD and ToF) satisfactory post-op outcome is not solely dependent on systolic $\mathrm{RV}$ and LV function. Early signs of LV diastolic dysfunction might need to be emphasized in this patient group.

\section{Purpose}

We used a novel MR speckle tracking method for MR gradient-echo loops to evaluate the LV for early signs of diastolic dysfunction, namely length of LV diastolic untwisting.

\section{Methods}

We studied 15 pts with TOF ( 6 mon- 45 y) post repair, 15 pts with ASD, VSD and CO ( $5 \mathrm{y}-37 \mathrm{y})$ and 8 healthy adults (24-35 y). MR images were acquired with an ECG gated $1.5 / 3 \mathrm{~T}$ Magnet with segmented gradient-echo cine-loop sequences (short/long/rotated axis) to cover the entire RV and LV. Images were analyzed offline by VVI (Siemens). RV size and function was correlated for each patient). LV myocardial strain, direction of twist and untwisting, time to peak twist and length to peak diastolic untwisting were measured and compared for each patient.

\section{Results}

In the CHD group a decrease in LV circ. strain (m-14.6\% $\pm 5.3 \%)$, and twist $\left(\mathrm{m}-7.2^{\circ} \pm 2.8^{\circ}\right)$ were found. Time to peak systolic twist was prolonged and more heterogeneous in CHD pts than in controls. Apical twist direction remained counterclockwise (ccw), but a loss of septal twist initiation was found. Time to peak diastolic untwisting was decreased and more variable in CHD pts (m 380 $\mathrm{ms} \pm 165 \mathrm{~ms}, \mathrm{p}=0.05)$. In healthy controls LV circ.strain was measured at $-18.5 \% \pm 7 \%$, and twist at $-9.6^{\circ} \pm 4.3^{\circ}(\mathrm{p}$ $=0.05)$. Time to peak systolic twist was less heterogeneous, twist direction uniformly ccw. Time to peak diastolic untwisting was significantly longer (320 ms $\pm 120 \mathrm{~ms}$ ) than in the ToF group Figure 1.

\section{Conclusion}

Not only the degree and length of systolic twist are affected in CHD post-op pts but also time to peak and length of diastolic untwisting. These findings could help evaluate the LV for early alterations in this pt group independent of $\mathrm{LV}$ systolic function. 


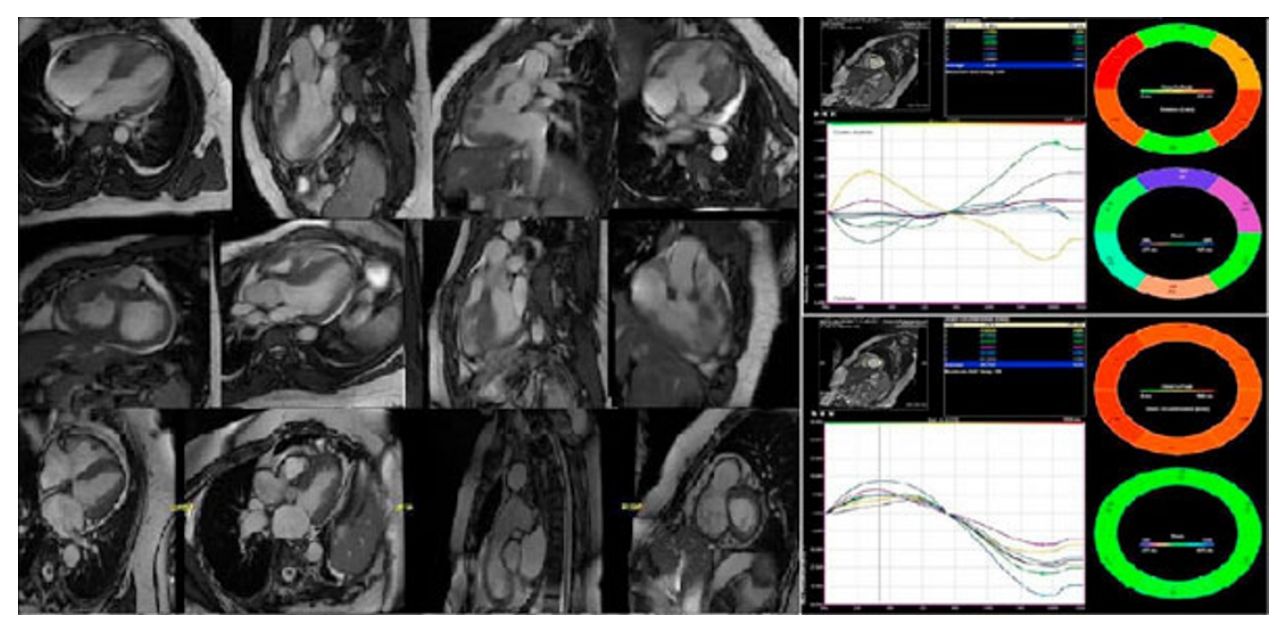

Figure I

Publish with Biomed Central and every scientist can read your work free of charge

"BioMed Central will be the most significant development for disseminating the results of biomedical research in our lifetime. " Sir Paul Nurse, Cancer Research UK

Your research papers will be:

- available free of charge to the entire biomedical community

- peer reviewed and published immediately upon acceptance

- cited in PubMed and archived on PubMed Central

- yours - you keep the copyright 